AIAA 92-3099

Internal Shock Interactions in Propulsion/Airframe Integrated Three-Dimensional Sidewall

Compression Scramjet Inlets

\author{
Scott D. Holland \\ and \\ John N. Perkins
}

AIAA/SAE/ASME/ASEE 28th Joint Propulsion

Conference and Exhibit

July 6-8, 1992

Nashville, Tennessee 


\title{
INTERNAL SIIOCK INTERACTIONS IN PROPULSION/AIRFRAME INTEGRATED THREE-DIMENSIONAL SIDEWALL COMPRESSION SCRAMJET INLETS
}

\author{
by
}

\author{
Scoll D. Holland ${ }^{*}$ and John N. Perkins $\ddagger$ \\ Department of Mechanical and Acrospace Engineering \\ North Carolina State University \\ Raleigh, North Carolina 27695
}

\begin{abstract}
The advantages and design requirements of propulsion/airframe integration for high Mach number flight have led to extensive study of the threc-dimensional sidewall compression scramjet inlet in recent years. Recent research publications have indicated testing over a broad range of Mach number ( 2 to 18) in a variety of test gases, such as air, helium, and tetrafluoromethane. Multiple experimental techniques have been employed to obtain detailed internal shock interaction data, performance data, and inlet starting limits. Computational fluid dynamics has been effectively used for preliminary parametric studies as well as in parallel with experiments to aid in the explanation of unusual or unexpected flow phenomena. Inlets of this genre afford a relatively simple, generic geometry while producing a highly complex, three-dimensional flow field dominated by shock/shock and shock/boundary layer interactions. While the importance of the viscous effects in high speed inlet interactions is recognized, the present work addresses in a parametric fashion the inviscid effects of leading edge sweep, sidewall compression, and inflow Mach number on the internal shock structure in terms of inlet compression and mass capture. In the process, the source of the Mach number invariance with leading edge sweep for a constant sidewall compression class of inlet is identified, and a previously undocumented spillage phenomenon in a constant effective wedge angle class of inlets is discussed.
\end{abstract}

\section{Nomenclature}

$\mathrm{CR}$ contraction ratio, $\mathrm{W} / \mathrm{g}$

$\mathrm{Cx}^{\prime}$ distance from throat entrance to cowl leading edge,

g throat gap, inch

\footnotetext{
* Post Doctoral Rescarch Associate, Aerospace Engineering Department, Member AIAA. Presently with the Experimental Hypersonics Branch/Space Systems Division, NASA Langley Research Center, Hampton, VA 23665. ¥ Professor, Aerospace Engineering, Associate Fellow AIAA.

Copyright (C) 1992 by Scott D. Holland. Published by the American Institute of Acronautics and Astronautics, Inc., will permission.
}

\begin{abstract}
H height of inlet, inch
$M_{1} \quad$ freestream Mach number

$M_{1 n}$ component of freestream Mach number normal to leading edge

$M_{1 p}$ component of freestream Mach number parallel to leading edge

$M_{2}$ resultant post-shock Mach vector

$\mathrm{M}_{2 \mathrm{n}}$ post-shock component of Mach vector normal to leading edge in plane of wedge

$M_{2 p}$ post-shock component of Mach vector parallel to leading edge in plane of wedge

$\mathrm{M}_{\mathrm{N}}$ component of inflow Mach vector normal to the shock sheet

$\mathrm{p}_{1}, \mathrm{p}_{2}$ static pressure upstream/downstream of shock, respectively, psia

$T_{1}, T_{2}$ static temperature upstream/downstream of shock, respectively ${ }^{\circ} \mathrm{R}$

$\mathrm{Tx}^{\prime} \quad$ distance from sidewall leading edge to throat, inch

$W$ inlet width at the sidewall leading edge, inch

$x$ axial distance measured from baseplate leading edge, inch

$x^{\prime} \quad$ axial distance measured from sidewall leading edge, inch

y lateral distance from inlet plane of symmetry, inch

$z \quad$ vertical distance from bottom surface, inch
\end{abstract}

Greek:

$\beta \quad$ angle measured in plane of wedge, $\mathrm{deg}$

$\Gamma \quad$ angle mcasured in plane of wedge, deg

$\gamma \quad$ ratio of specific heats

$\delta \quad$ sidewall compression angle, deg

$\delta_{\text {eff }}$ effective sidewall compression angle, measured normal to sidewall leading edge, deg

$\theta_{\text {eff }}$ effective oblique shock angle, measured normal to sidewall leading edge, deg

$\hat{\zeta} \quad$ leading edge swcep angle, deg

$\zeta \quad$ spillage angle, deg

\section{Introduction}

High Mach number propulsion for airbreathing vehicles such as the National Aero-Space Plane (X-30) is presently proposed to be accomplished with highly integrated supersonic combustion ramjets (for example, Refs. 1-2). Careful design of primary engine components such as the inlet is necessary to exploit effectively the potential of 
propulsion-airframe integration. In particular, the threedimensional sidewall compression scramjet inlet has been under study for many years and continues to be of interest. Inlets of this genre have been studied in earlier years experimentally for the overall performance characteristics (at Mach numbers between 2 and 6 ) and as part of a subscale engine system by Trexler, et al. (Refs. 3-6). The inlets have more recently been studied in a variety of test gases and a broad range of Mach numbers, e.g. Mach 4 air by Kanda, et al. (Ref. 7), Mach 18 and 22 helium by Trexler, et al. (Ref. 4), Mach 6 tetrafluoromethane by Holland and Perkins (Ref. 8), and Mach 10 air by Holland, et al. (Refs. 9-10). The works of Kanda, et al.(Ref. 7) in Mach 4 air and Vinogradov, et al. (Ref. 11) in Mach 2-6 air also demonstrate an interest in sidewall compression inlets by the Japanese and Sovicts, respectively.

Recent work has also highlighted the use of computational fluid dynamics for inlet research. Kumar (Ref. 12) has developed and evolved a three-dimensional Reynolds averaged Navier-Stokes code primarily for internal flow configurations. Favorable comparisons between experiment and computation (using this code) have been presented by Kumar and Trexler (Ref. 13) on a generic scramjet engine configuration at a nominal Mach number of 4 and by Holland (Ref. 10) at Mach 10. Analyses of subscale engines and combustion processes have also been performed computationally. Srinivasan, McClinton, and Kamath (Ref. 14) presented results using a version of Kumar's code to compute the three-dimensional turbulent, reacting flow through the entire Langley Parametric Scramjet Engine at an inflow Mach number of 6.25. Sekar, Thomas, and Srinivasan (Ref. 15) have also used this code to compute flow in one of Langley's Arc-Heated Scramjet Test Facility's Mach 6 nozzles and subsequently through the Parametric Scramjet Inlet. Kumar, Singh, and Trexler (Ref. 16) have performed a numerical study of the effects of reverse sweep on a scramjet inlet perfornance at Mach 4.5.

Thus it is evident that extensive study has been devoted to the three dimensional sidewall compression scramjet inlet for a variety of test conditions. Although the swept wedge sidewalls are geometrically simple, the internal shock/shock and shock/boundary layer interactions are inherently highly three-dimensional. A basic understanding of the configuration and global flow phenomena is a necessary foundation to the study of the complex viscous interactions presented in many of the previously mentioned studies. While the importance of the viscous effects in high speed inlet interactions is recognized, the present work addresses in a parametric fashion the inviscid effects of leading edge sweep, sidewall compression, and inflow Mach number on the internal shock structure in terms of inlet compression and mass capture. In the process, the source of the Mach number invariance with leading edge sweep for a constant sidewall compression class of inlet is identified, and a previously undocumented spillage phenomenon in a constant effective wedge angle class of inlets is discussed.

\section{Propulsion Airframe Integration}

Maintaining the flight of an airbreathing hypersonic cruise vehicle such as the $\mathrm{X}-30$ requires a propulsion system which is highly efficient. The advantages of propulsion airframe integration as a means of obtaining this increased efficiency have been well recognized for many years (Ref. 17). This concept makes use of the forebody bow shock, which precompresses the flow upstream of the inlet entrance (Figure 1). Since an inlet would be limited by the dimensions of the shock layer, and since the inlet should process a maximum amount of the oncoming stream, this concept requires ingestion of the forebody boundary layer. Further compressive turning in the vertical direction (normal to the surface), as in two-dimensional inlets, would greatly increase the risk of scparation upstream of the inlet entrance due to the shock-boundary layer interaction. A possible solution to the problem involves the use of the threedimensional sidewall compression inlet.

\section{Configuration Description}

The three-dimensional sidewall compression inlet accomplishes further compression in the horizontal direction by wedge shaped sidewalls, reducing the total in-plane turning the flow must encounter to obtain the desired compression. A sketch of the inlet configuration is presented in Figure 2. The leading edges of the sidewalls are swept both to reduce the aerothermal loads on the leading edges and to provide a window for spillage at the lower Mach numbers to aid in starting the inlet; the mechanism for this flow downturning (spillage) is discussed in the next section. The leading edge sweep angle $\Lambda$ is measured relative to an unswept leading edge, which protrudes normal to the bascplate.

The sidewall compression angle $\delta$ (measured in a plane parallel to the baseplate) is commonly fixed at 6 degrees as a result of a trade-off study (Ref. 6), a compromise between larger compression angles leading to stronger internal shocks and increased risk of boundary layer separation and smaller compression angles leading to weaker internal shocks but requiring the inlet to be longer to obtain the same compression, and thus imposing a size and weight penalty on the inlet. The entire compression surface is swept, culminating in a swept entrance to the throat region. The length of the swept compression surface is denoted Tx' (see Figure 2). Since the intersection of the constant area throat and the swept compression surface is a line swept at the leading edge sweep angle, the length $\mathrm{Tx}^{*}$ is constant regardless of the distance from the baseplate. The distance $T x^{\prime}$ is measured axially rather than along the wetted surface, although for a 6 degree compression, the difference is only slight. In order to more easily compare data from various leading edge sweep configurations, a new axial coordinate $x$ is introduced, where $x^{\prime}$ is the distance (measured axially) from the leading edge at any given horizontal plane. Thus, $x^{\prime} / T x^{\prime}=0.20$ represents a crossflow plane (which is also 
swept at the leading edge sweep angle) located $20 \%$ of the distance between the leading edge and the throat entrance, regardless of the leading edge sweep angle.

The contraction ratio is defined as the ratio of the entrance area to the throat area. In many studies, the height at the entrance and throat are the same so that the contraction ratio reduces to the ratio of the entrance width to the throat gap, W/g.

The definition of the cowl position is made simpler by the introduction of the variable Cx' (see Figure 2), which is the distance between the cowl leading edge and the beginning of the throat region (measured in the plane of the cowl). Thus, the ratio $\mathrm{Cx}^{\prime} / \mathrm{Tx}^{\prime}$ defines the forward extent of the cowl ahead of the throat as a percentage of the length of the compression surface. Thus $\mathrm{Cx}^{\prime} / \mathrm{T} \mathrm{x}^{\prime}=0.0$ (referred to as a $0 \%$ cowl) indicates that the cowl is at the throat, $C x^{\prime} / T x^{\prime}=0.50$ (referred to as a $50 \%$ cowl) indicates that the cowl leading edge is located at the midpoint of the compression surface, and $\mathrm{Cx}^{\prime} / \mathrm{T} \mathrm{x}^{\prime}=1.0(100 \%$ cowl) indicates that the cowl leading edge coincides with the sidewall leading edge.

\section{Basic Flow Phenomena}

Contraction Ratio Effects. When the flow encounters the wedge-shaped sidewalls, a complex shock structure develops. Consider first the inviscid flow past a pair of infinitely tall unswept (2-D) wedges located opposite one another, i.e. an unswept inlet of infinite height. A pair of shock sheets extend from the leading edge of the wedges, cross at the centerline, and then impinge on the sidewalls. Inviscidly, the shocks cancel if they are incident at the shoulder in the thmat; otherwise they continue to reflect if they strike ahead of the shoulder. Figure 3 illustrates the three possibilities: shock on shoulder, shock ahead of shoulder, and shock after shoulder. This reflected shock pattern has been demonstrated computationally for a sidewall compression inlet of similar design in Mach 5 air (perfect gas) for a leading edge sweep of $45^{\circ}$ (Ref. 18). The inviscid shock pattern is largely dictated by the sidewall compression angle, $\delta$, the inflow Mach number, $M_{1}$, and the contraction ratio, $C R(=W / g$, sce Figure 2). The sidewall compression angle and the inflow Mach number determine the inviscid shock angle through oblique shock theory. For a fixed sidewall compression angle and Mach number (and hence fixed shock angles), the location of the shock impingement point is determined by the distance between the sidewalls, or in other words, the contraction ratio. Thus, increasing the contraction ratio (bringing the sidewalls closer together) moves the sidewall shock impingement points forward, causing the internal flow to encounter a greater number of reflected oblique shocks and increasing the compression of the inlet.

Leading Edge Sweep Effects. The addition of leading edge sweep to the sidewalls causes the shock sheets generated by the leading edge, the line along which the shocks intersect on the centerline, and the line along which the shocks impinge on the sidewalls to be swept at the lcading edge swcep angle. Shock interactions of this naturc occur along lines of constant leading edge sweep angle. This trend has been demonstrated both computationally (see for example Figures 5 and 6 of Ref. 18 or Figures $8.1 .1 \mathrm{~b}-8.1 .10 \mathrm{~b}$ of Ref. 10) and experimentally (see Figures 7.1.1.1-20 of Ref. 10).

Sweeping the leading edges aft has an additional effect of turning the flow downward toward the cowl as the flow passes through the swept shocks. This turning is shown qualitatively by considering the inviscid flow between two infinitely long swept wedges (i.e. neglecting end effects) using oblique shock theory, modified for the inclusion of leading sweep. The addition of leading edge sweep requires that another component of the inflow Mach number (namely, the component parallel to the leading edge) be calculated through the shock. Figure 4 shows the oncoming freestream Mach vector broken into components parallel and normal to the swept wedge. Two-dimensional oblique shock theory may be applied directly to the normal component $\left(\mathrm{M}_{1 \mathrm{n}}\right)$ to determine its post-shock components, noting that the effective wedge angle $\left(\delta_{\mathrm{eff}}\right)$, the wedge angle measured normal to the leading edge, is given by

$$
\delta_{\mathrm{eff}}=\tan ^{-1}\left(\frac{\tan \delta}{\cos \Lambda}\right)
$$

and is greater than $\delta$. The equations to find the resultant Mach vector behind the oblique shock for the $2-D$ theory may be found in several texts (see for example Anderson (Ref. 19)) where three equations may be combined to give (in the notation of this study) $M_{2 n}$ in terms of $M_{1 n}$, the ratio of specific heats, and the effective wedge and shock angles as:

$$
M_{2 n}=\frac{\left\{\frac{M_{1 n}^{2} \sin ^{2} \theta_{e f f}+\left[\frac{2}{(\gamma-1)}\right]}{\left[\frac{2 \gamma}{(\gamma-1)}\right] M_{1 n}^{2} \sin ^{2} \theta_{e f f}-1}\right\}^{1 / 2}}{\sin \left(\theta_{e f f}-\delta_{e f f}\right)}
$$

The parallel component $\left(\mathrm{M}_{1 \mathrm{p}}\right)$ must be treated separately. It should be noted that while the component of velocity parallel to the shock remains unchanged through the shock, the Mach number associated with that velocity vector decreases due to the increase in static temperature and hence the speed of sound across the shock, as

$$
M_{2 p}=M_{1 p}\left(\frac{T_{1}}{T_{2}}\right)^{1 / 2}=M_{1} \sin \Lambda\left(\frac{T_{1}}{T_{2}}\right)^{1 / 2}
$$


With the components behind the shock known, the resultant magnitude and direction of the Mach vector can be determined. The spillage angle $\zeta$ can be determined as the difference between two angles, $\Gamma$ and $\beta$, in the plane of the wedge, as shown in Figure 4 . The angle between the lcading edge and the $x-z$ plane measured in the plane of the wedge is denoted as $\Gamma$ and is given by:

$$
\Gamma=\sin ^{-1}\left(\frac{\sin \delta}{\sin \delta_{\mathrm{ef} f}}\right)
$$

The angle which the resultant makes with the leading edge in the plane of the wedge $\beta$ is given by:

$$
\beta=\tan ^{-1}\left(\frac{M_{2 n}}{M_{2 p}}\right)=\tan ^{-1}\left(\frac{M_{2 n}}{\left(T_{1} / T_{2}\right)^{1 / 2} M_{1} \sin \Lambda}\right)
$$

Clearly the difference between these two angles is the spillage angle $\zeta$.

$$
\begin{aligned}
\zeta & =\Gamma-\beta \\
& =\sin ^{-1}\left(\frac{\sin \delta}{\sin \delta_{\mathrm{eff}}}\right)-\tan ^{-1}\left(\frac{M_{2 n}}{\left(\mathrm{~T}_{1} / \mathrm{T}_{2}\right)^{1 / 2} \mathrm{M}_{1} \sin \Lambda}\right)[6]
\end{aligned}
$$

An altemate but equivalent definition of the spillage angle is the difference between the angle made by the resultant $\mathrm{M}_{2}$ and its component normal to the leading edge $M_{2 n}$ and the angle made by a $z=$ constant plane and $M_{2 n}$, both measured in the plane of the wedge (see Figure 4). This alternate equation may be more convenient for some applications is hence provided for reference.

$$
\zeta=\tan ^{-1}\left(\frac{M_{2 p}}{M_{2 n}}\right)-\tan ^{-1}\left(\cos \delta_{\text {eff }} \tan \Lambda\right)
$$

Cowl Placement Effects. While spillage is important in helping the inlet start, favorable mass capture characteristics at cruise are of utmost importance for efficient operation. The flow spillage can be tempered by the position of the cowl. Compared to an aft placement, the cowl forward configuration captures more of the mass tumed downward by the internal shocks. It is expected that a shock would develop on the cowl lip inside the inlet as the downturned flow impinges on the cowl and is turned back parallel to the cowl surface, further increasing the compression and decreasing the tolal pressure recovery of the inlet. As the cowl is placed in a progressively more forward position, it is expected that this cowl shock would influence a greater fraction of the exit plane (combustor entrance), leading to greater exit plane flow nonuniformity as well as the increased degradation of total pressure recovery.

Yiscous and End Effects. While a detailed discussion of the viscous effects are beyond the scope of the present paper, viscous effects and end effects can play a significant (if not dominant) role in determining the internal flow structure. Particularly when the inlet height is small (compared to length), end effects can be observed to influence much of the inlet flow field. It was noted in Ref. 20 that in the bottom $10 \%$ of the inlet, a strong downturning can be observed (particularly in the low momentum sidewall boundary layer) due to the pressure differential between the compressed postglancing shock region inside the inlet and the uncompressed flow just below the inlet. Another key feature of the internal interactions is the strong induced crossflow in the baseplate boundary layer, which has been observed to influence the flow well upstream of the glancing shocks. In some cases, the induced crossflow has led to a separation which propagates upstream of the inlet entrance (see, for example, Ref. 10).

\section{Besults}

With the equations thus set forth, the effects of leading cdge sweep on $M_{1 n}, \delta_{\text {eff, }}, \theta_{\text {eff, the component of the inflow }}$ Mach number normal to the shock sheet $\left(M_{N}=M_{1} \cos \Lambda \sin \theta_{e f f}\right)$, the leading edge shock compression $\mathrm{P}_{2} / \mathrm{P}_{1}$, and the spillage angle $\zeta$ can be conveniently determined. By definition, $M_{1 n}$ decreases as the cosine of the leading edge sweep angle. For fixed $\delta$, the elfective compression angle $\delta_{\text {eff }}$ (Figure 5) increases as the inverse tangent function and is not a function of Mach number (note Eqn [1]). The decrease in $M_{1} n$ and the increase of the effective wedge angle $\delta_{\text {eff }}$ with increasing leading edge sweep $\Lambda$ tend to cancel to yield a nearly constant inviscid shock strength. The variation of the normal Mach number, the component of the inflow Mach number normal to the shock sheet $\left(M_{N}=M_{1 n} \sin \theta_{e f r}\right)$, with leading edge sweep is shown in Figure 6 and the leading edge shock compression $\mathrm{P}_{2} / \mathrm{P}_{1}$ is shown in Figure 7 for a family of inflow Mach numbers. $M_{1 n}$ is observed to decrease and $\sin \theta_{\text {eff }}$ to increase such that even for $\Lambda=70^{\circ}$, the normal Mach number has varied by less than $0.5 \%$ at Mach 10 . The compression across the leading edge shock $\left(\mathrm{P}_{2} / \mathrm{P}_{1}\right)$ is likewise invariant with leading edge sweep angle. The present work demonstrates that inviscidly it is the compensating effects of decreasing $M_{1 n}$ and increasing effective wedge angle $\delta_{\text {eff }}$ which yields the invariance in $M_{N}$ (and hence shock strength) with increased leading edge sweep.

The spillage angle $\zeta$ and the percent mass capture based on spillage from the first shock bay (i.e. the region labeled "2" in Figure 3) are presented in Figures 8 and 9. respectively. This spillage is shown three-dimensionally in Figure 10. Since the computation of percent mass capture is configuration specific, the configuration chosen for the analysis is that of Ref. 10 (inlet height of 4 inches, $T x^{\prime}=9.5$ inches) at a contraction ratio of 5 . The mass capture is observed to increase with increasing inflow Mach number for two reasons. First, the flow deflection (or spillage) angle $\zeta$ is decreased with increasing Mach number, and second, since at high Mach numbers the shocks lie closer to the sidewalls, the spillage area (see Figure 11) is decreased. 
The spillage of the inlet due to all of the internal shocks has been computed, and the percent mass capture for a family of contraction ratios and cowl positions at Mach 4 and 10 is presented in Figures 12 and 13, respectively. It is again noted by comparing the figures that the mass capture increases with increasing inflow Mach number for the previously stated reasons. The cowl position is also observed to have a strong influence on the mass capture, since a forward cowl placement prevents more of the flow turned downward by the internal glancing shocks from spilling. The contraction ratio has a less direct influence on spillage. Coupled with the inflow Mach number and the sidewall compression angle, the contraction ratio determines the number of internal reflected shocks the flow will encounter upstream of the cowl leading edge. For example, at $\mathrm{CR}=9$ and $25 \%$ cowl, the flow entering the inlet encounters five compressions upstream of the cowl leading edge at an inflow Mach number of 4 compared to only two compressions at an inflow Mach number of 10. Each of these compressions incrementally increases the flow deffection: $\zeta$ behind each of the five compressions (shock bays 2 through 6 -- see Figure 3) for the Mach 4 inflow and $\Lambda=45^{\circ}$ are $1.5^{\circ}, 2.7^{\circ}, 4.6^{\circ}, 6.4^{\circ}$, and $9.1^{\circ}$, compared to $0.8^{\circ}$ and $1.2^{\circ}$ for the Mach 10 inflow. Thus, an increase in contraction ratio, a decrease in inflow Mach number, and an aft cowl placement are all observed to yicld a decrease in the total mass capture of the inlet.

Variable Shock Strength Configurations. It was previously noted that the shock strength remained relatively constant with leading edge sweep for a fixed sidewall compression angle. If instead the effective wedge angle is kept constant for a range of leading edge sweep, a class of inlets yiclding a variable shock strength with leading edge sweep is generated. Figures 14-18 present a similar set of data to that of Figures 5-9. (Again, a nominal inflow Mach number of 10 was chosen for the discussion, however, families of curves representing a range of inflow Mach numbers are presented.) Since the effective wedge angle rather than the wedge angle is fixed $\left(10^{\circ}\right.$ for this example), Figure 14 shows the variation of the wedge angle $\delta$ (measured in a horizontal plane) necessary to maintain a constant effective wedge angle with leading edge sweep. It should be noled that since the wedge angle measured in the horizontal plane must decrease with leading edge sweep to maintain a constant $\delta_{\mathrm{e} f}$, the wedge angle $\delta$ becomes quite small at high leading edge sweep angles. From a practical standpoint this creates a difficult structural problem for highly swept inlets of this class due to the aerothermal loading on the thin leading edge. The normal Mach number and pressure ratio across the shock demonstrate the variability of shock strength with leading cdge sweep for this class of inlet. Over a range of leading edge sweep between $0^{\circ}$ and $72^{\circ}$, Figure 15 shows a decrease in normal Mach number from 2.5 to 1.4 for a Mach 10 inflow. The shock compression (Figure 16) decreases from approximately 7.1 to 2.1, with an attendant increase in post shock Mach number magnitude $\mathrm{IM}_{2}$ l from 6.6 to 8.9. The trends are unchanged with Mach number, although the decreases become less significant at lower inflow Mach numbers. Both the spillage angle (Figure 17) and the percent mass capture (Figure 18) demonstrate an unusual phenomenon. An inflection point is observed in the $\zeta, \Lambda$ relationship which leads to a relative maximum for the inflow Mach numbers above 8. For the Mach 10 inflow, the spillage appears to reach a maximum at approximately $\Lambda=54^{\circ}$, beyond which the percent mass capture actually improves. The spillage is affected primarily by two geometric factors: the leading edge sweep, and the sidewall compression angle. It has already been demonstrated that for a class of inlets with constant sidewall compression angle, the spillage increases with leading edge sweep. However, for the constant $\delta_{\mathrm{eff}}$ class of inlets, the sidewall compression angle also decreases dramatically with leading edge sweep. At high sweep (i.e., $\Lambda>54^{\circ}$ ), the effect of loss of sidewall compression begins to dominate the spillage effects of increased leading edge sweep, leading to the improvement in mass capture with $\Lambda$ for large $\Lambda$. At Mach 4 , the improvement in spillage for the entire inlet (Figure $19)$ is never realized since, at the high leading edge sweeps necessary to obtain the improvement, the reflected shocks have become detached (formed a normal shock) upstream of the throat, thereby making supersonic combustion impossible. At Mach 10 (Figure 20), a slight improvement in mass capture at high $\Lambda$ is noted compared to the constant $\delta=6^{\circ}$ configuration. (A similar improvement in capture characteristics of the constant $\delta$ configuration can be obtained if the $\delta$ is decreased dramatically. This does not prove to be a practical consideration, since a decrease in $\delta$ comes at a significant loss of inlet compression.)

\section{Conclusions}

The three-dimensional sidewall compression scramjet inlet has been the subject of extensive study in recent years. The present work has provided a detailed description of the generic configuration and the inviscid internal shock structure. A summary of the inlet characteristics is as follows.

- The inviscid internal shock pattern is largely dictated by the sidewall compression angle, $\delta$, the inflow Mach number, $M_{1}$, and the contraction ratio, $C R$. The sidewall compression angle and the inflow Mach number determine the inviscid shock angle through oblique shock theory. For a fixed sidewall compression angle and Mach number (and hence fixed shock angles), the location of the shock impingement point is determined by the distance between the sidewalls, or in other words, the contraction ratio. Thus, increasing the contraction ratio (bringing the sidewalis closer together) increases the compression of the inlet by causing the internal flow to encounter a greater number of reflected oblique shocks.

- A common feature in many of the recent inlet tests is an aft swept leading edge. The inclusion of leading edge sweep causes the entire internal shock structure to be swept at the leading edge sweep angle. Inviscidly, the sweep has 
the additional effect of turning the flow downward, providing a window for spillage at the lower Mach numbers. This spillage is important for the inlet starting process, however at cruise, a high mass capture is desirable. Since the internal shocks lie closer to the sidewalls at higher Mach numbers, the spillage window is partially closed, and a variable geometry characteristic is realized for a fixed geometry inlet. Additionally, forward cowl placement can be used to prevent some of the flow spillage, thereby increasing the mass capture.

- It was further found that a class of inlets with varying leading edge shock strength could be developed by maintaining a constant effective wedge angle rather than a constant sidewall wedge angle while increasing leading edge swcep. Inlets so defined are characterized by decreased compression and decreased sidewall wedge angle (which becomes prohibitively small when the leading edge sweep exceeds $60^{\circ}$ ) with increased leading edge sweep. For this class of inlet however, an unusual spillage phenomenon was observed in that the spillage reached a maximum and then began to decrease with increasing leading edge sweep. The spillage is affected primarily by two factors: the leading edge sweep, and the sidewall compression angle. It has already been demonstrated that for a class of inlets with constant sidewall compression angle, the spillage increases with leading edge sweep. However, for the constant $\delta_{\text {eff }}$ class of inlets, the sidewall compression angle also decreases dramatically with leading edge sweep. For large lcading edge sweep, the effect of loss of sidewall compression begins to dominate the enhanced spillage effects of increased leading edge sweep, leading to the improvement in mass capture at large sweep. At Mach 4, this improvement in total mass capture was not realized due to shock detachment upstream of the throat at high leading edge sweep, and at Mach 10 , only a slight improvement over the constant wedge angle class of inlets was noted at very large leading edge sweep.

Thus the source of the Mach number (and hence shock strength) invariance with leading edge swecp for a constant sidewall compression class of inlet has been identified, and a previously undocumented spillage phenomenon in a constant effective wedge angle class of inlets has been discussed.

\section{Acknowledgements}

This work was supported in part by NASA Grant NCC1153.

\section{References}

1. Williams, R. M.: National Aero-Space Plane: Technology for America's Future. Acrospace America, Nov. 1986 , p. 18.

2. Kandebo, Stanley W.: "Researchers Pursue X-30 Spaceplane Technologies for 1990 Evaluation."
Aviation Weck and Space Technology, August 8, 1988, pp. 49-53.

3. Trexler, Carl A.: Inlet Performance of the Integrated Langley Scramjet Module (Mach 2.3 to 7.6). AIAA/SAE 1lith Propulsion Conference, Sept. 29-Oct. 1, 1975, Anaheim, CA, AIAA-75-1212.

4. Trexler, Carl A.: Tests of Two Sidewall-Compression Scramjet Inlets at Mach 18.1 to 21.6 in Helium. NASP TM 1018, May 1988.

5. Trexler, Carl A.: Inlet Starting Predictions for SidewallCompression Scramjet Inlets. AIAA/SAE/ASME/ ASEE 24th Joint Propulsion Conference, Boston, MA, July 11-13, 1988. AIAA-88-3257.

6. Trexler, Carl A. and Souders, Sue W.: Design and Performance at a Local Mach Number of 6 of an Inlet for an Integrated Scramjet Concept. NASA TN D7944, August 1975.

7. Kanda, T., Komuro, T., Masuya, G., Kudo, K., Murakami, A., Tani, K., Wakamatsu, Y., and Chinzei, N.: Mach 4 Testing of Scramjet Inlet Model. AIAA/ASME/SAE/ASEE 25th Joint Propulsion Conference, Monterey, CA, July 10-12, 1989, AIAA89-2680.

8. Holland, Scott D., and Perkins, John N.: Mach 6 Testing of Two Generic Three-Dimensional Sidewall Compression Scramjet Inlets in Tetrafluoromethane. AIAA 28th Aerospace Sciences Meeting, January 8-11, 1990. Reno, NV, AIAA-90-0530.

9. Holland, Scott D., Hodge, Jeffrey S., and Perkins, John N.: Wind Tunnel Blockage Study of a Generic ThreeDimensional Sidewall Compression Scramjet Inlet at Mach 10. AIAA 29th Aerospace Sciences Meeting, January 7-10, 1991, Reno, NV, AIAA-91-0294.

10. Holland, Scott D.: A Computational and Experimental Investigation of a Three-Dimensional Hypersonic Scramiet Inlet Flow Field. Ph.D. Dissertation, North Carolina State University, March 1991.

11. Vinogradov, V., Stcpanov, V., and Alexandrovich, E.: Numerical and Experimental Investigation of AirframeIntegrated Inlet for High Velocities. AIAA/ASME/SAE/ASEE 25th Joint Propulsion Conference, Monterey, CA, July 10-12, 1989, AIAA89-2679.

12. Kumar, A.: Numerical Simulation of Scramjet Inlet Flow Fields. NASA TP-2517, May 1986.

13. Kumar, Ajay, and Trexler, Carl A.: Analysis and Performance of Scramjet Inlets Utilizing a Three- 
Dimensional Navier-Stokes Code. 88 N14936, In Langley Symposium on Aerodynamics, Vol. 1, pp. $187-208$, avail. $88 \mathrm{~N} 14926$.

14. Srinivasan, S., McClinton, C. R., and Kamath, P. S.: Numerical Simulation of Flow Through the Langley Parametric Scramjet Engine. SAE Aerospace Technology Conference and Exposition, Anaheim, CA, September 25-28, 1989, SAE-892314.

15. Sekar, B., Thomas, S., and Srinivasan, S.: A Numerical Parametric Study of a Scramjet Inlet in a Mach 6 Arc Heated Test Facility. 28th Aerospace Sciences Meeting, Reno, NV, January 8-11, 1990, AIAA-90-0531.

16. Kumar, A., Singh, D. J., and Trexler, C. A.: A Numerical Study of the Effects of Reverse Sweep on a Scramjet Inlet Performance. AIAA/SAE/ASME/ASEE 26th Joint Propulsion Conference, Orlando, FL, July 16-18, 1990, AIAA-90-2218.

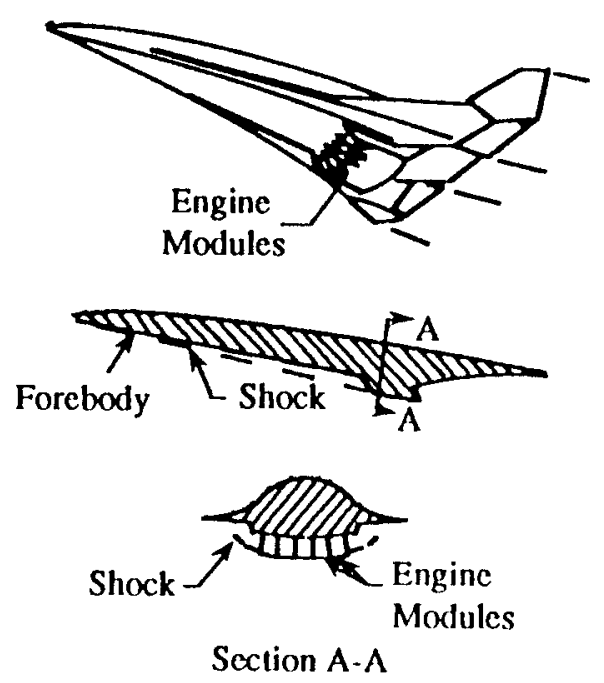

Figure 1: Propulsion Airframe Integration
17. Henry, John R. and Anderson, Griffin Y.: Design Considerations for the Airframe-Integrated Scramjet. NASA TM X-2895, Dec. 1973.

18. Kumar, A.: Three-Dimensional Inviscid Analysis of the Scramjet Inlet Flow Field. AIAA 20th Aerospace Sciences Meeting, Orlando, FL, Jan. 11-14, 1982. AIAA-82-0060.

19. Anderson, John D., Jr.: Modern Compressible Flow. McGraw-Hill, 1982.

20. Holland, Scott D., and Perkins, John N.: Contraction Ratio Effects in a Generic Three-Dimensional Sidewall Compression Scramjet Inlet: A Computational and Experimental Investigation. AIAA 22nd Fluid Dynamics, Plasma Dynamics, and Lasers Conference, June 24-26, 1991, Honolulu, HI, AIAA-91-1708.

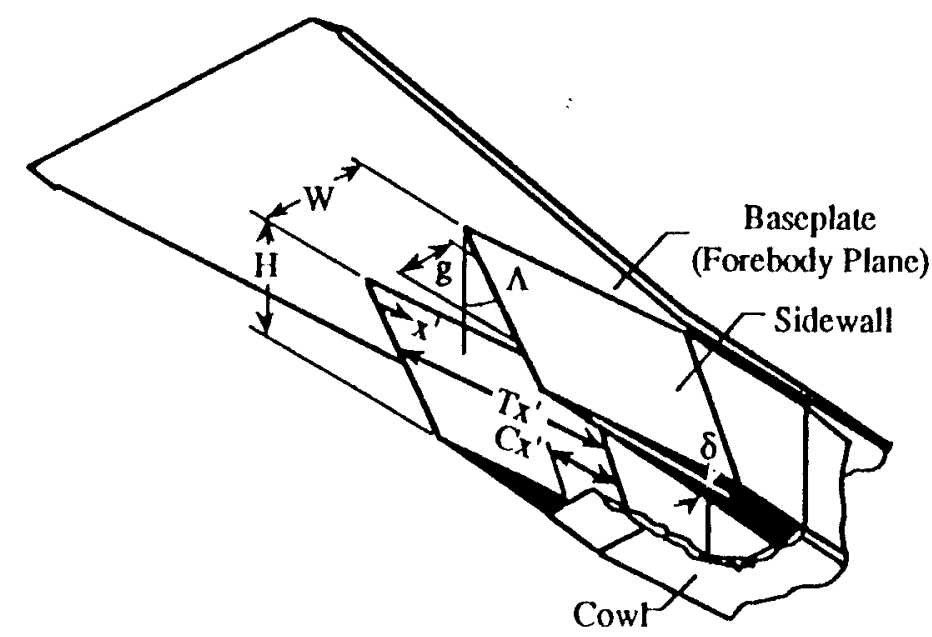

Figure 2: Inlet Model Shown in Flight Orientation 


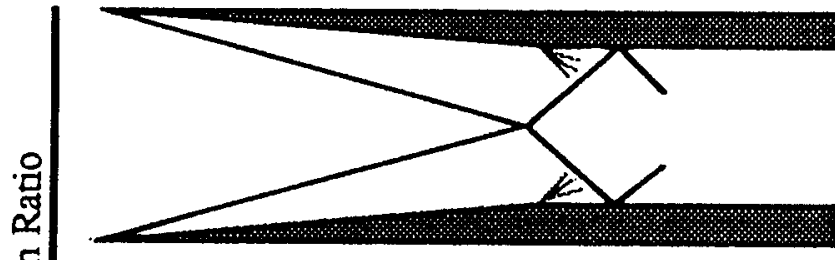

(a)

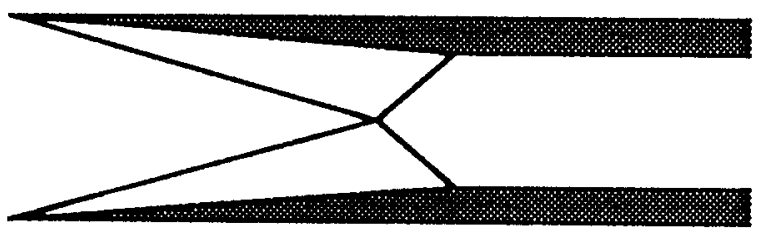

(b)

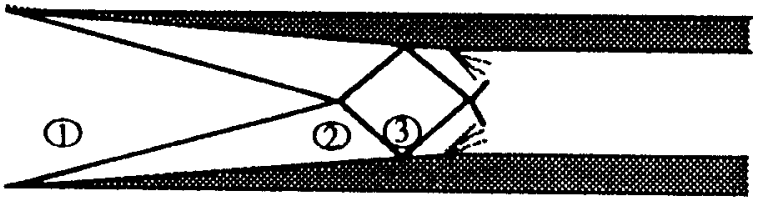

(c)

Figure 3: Effects of Increasing Contraction Ratio on Shock

Structure:

(a) Shock aft of shoulder

(b) Shock on shoulder

(c) Shock ahead of shoulder

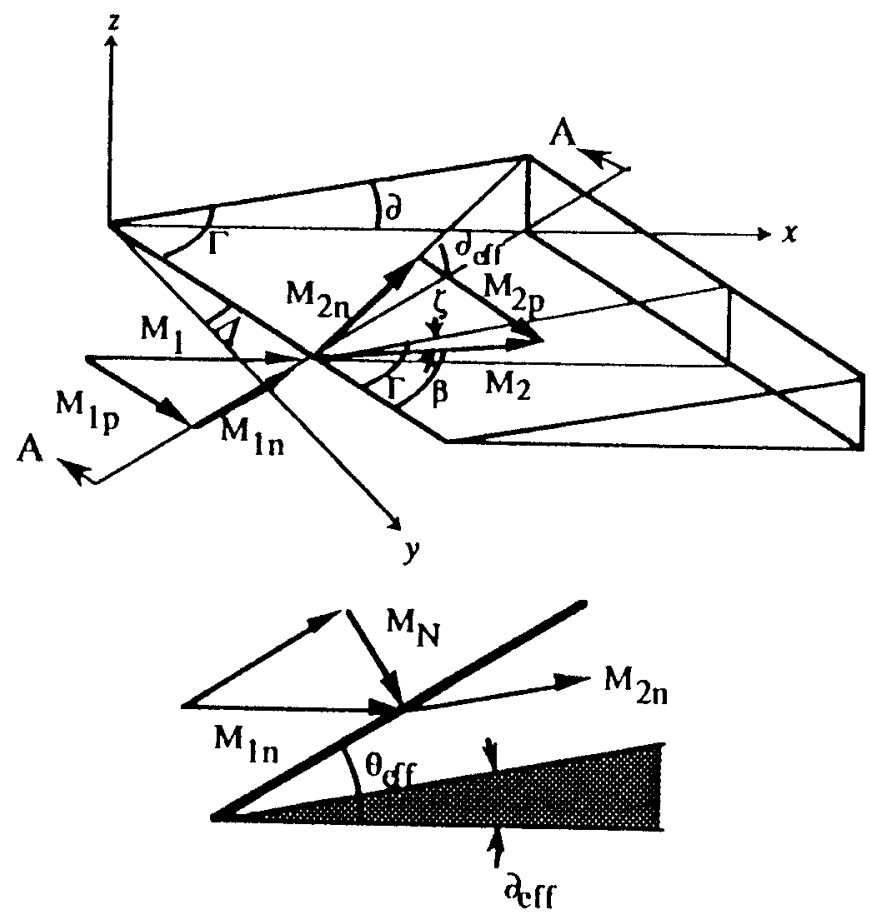

Section A-A

Figure 4: Mach Number Components for Modificd TwoDimensional Oblique Shock Theory

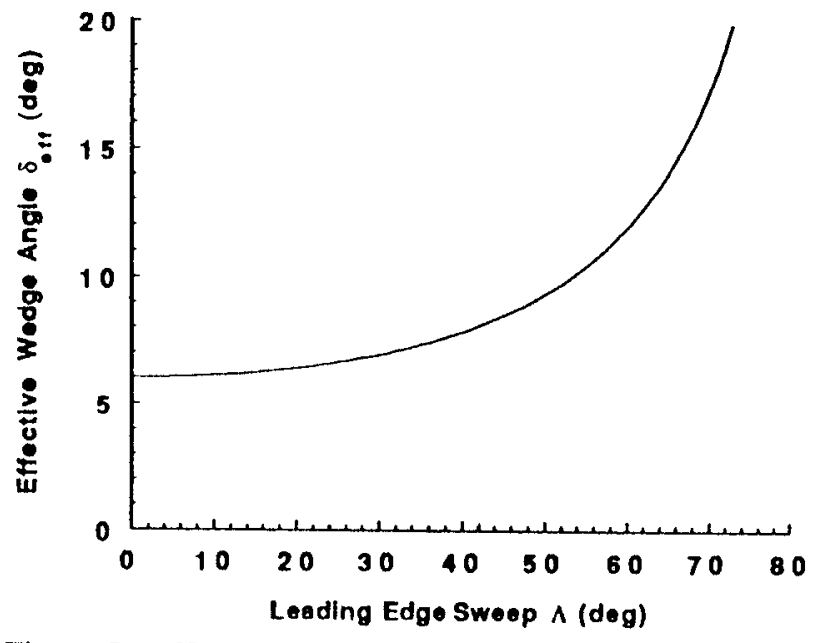

Figure 5: Effective Sidewall Compression Angle as a Function of Leading Edge Sweep

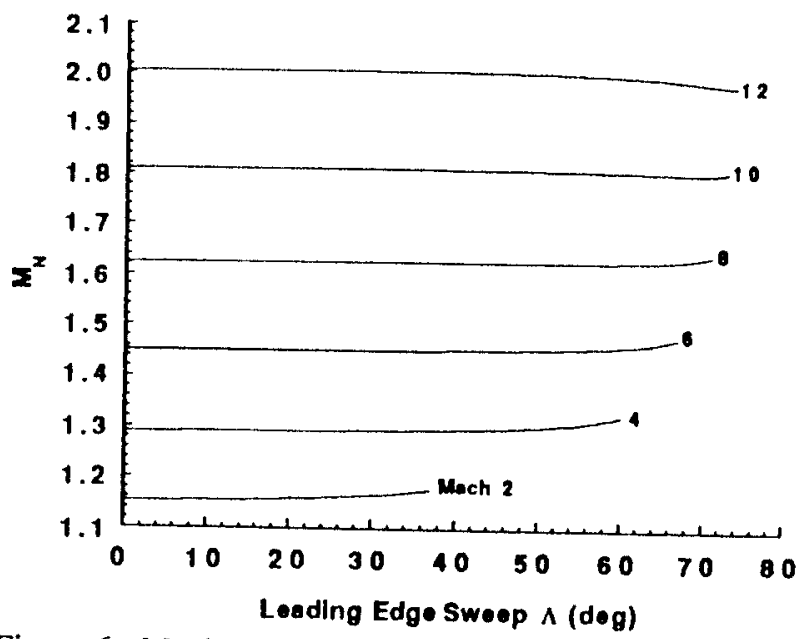

Figure 6: Mach Component Normal to Sidewall Shock Shect as a Function of Leading Edge Swecp 


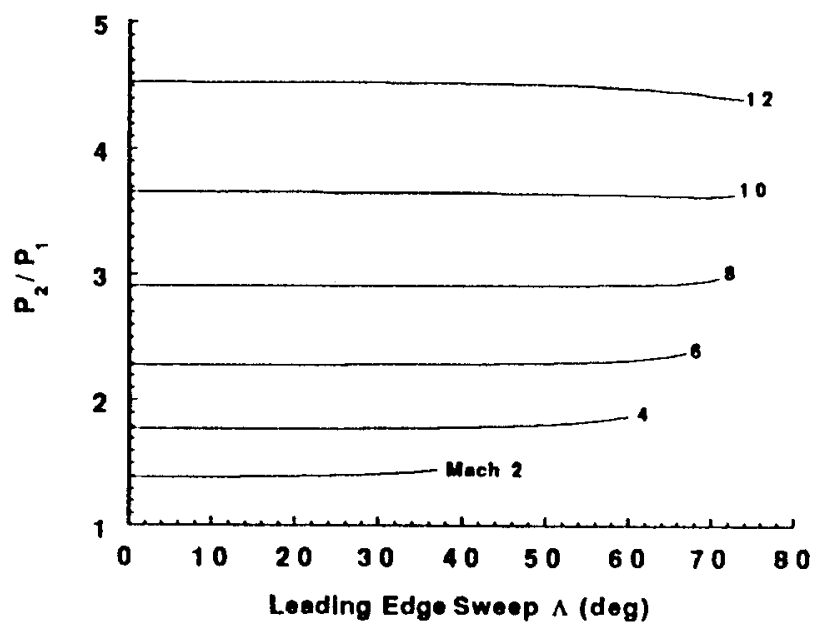

Figure 7: Compression Across Leading Edge Shock as a Function of Leading Edge Sweep

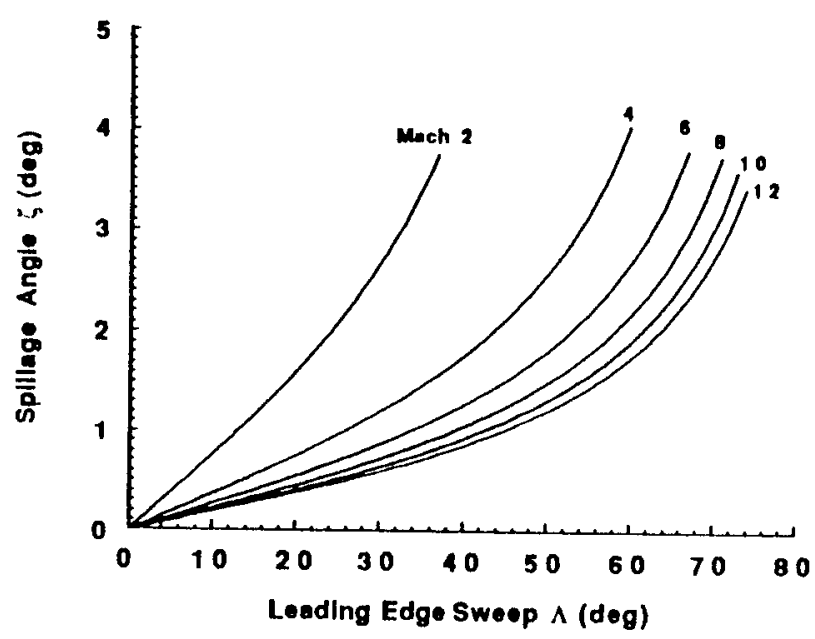

Figure 8: Spillage Angle Induced by Leading Edge Shock as a Function of Leading Edge Swecp

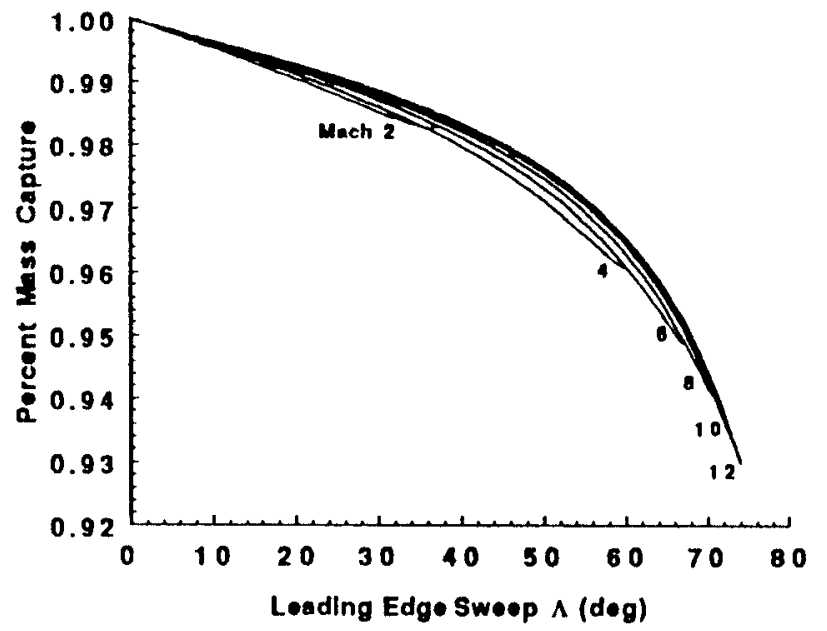

Figure 9: Percent Mass Capture Resulting from Spillage Induced by Leading Edge Shock as a Function of Sweep

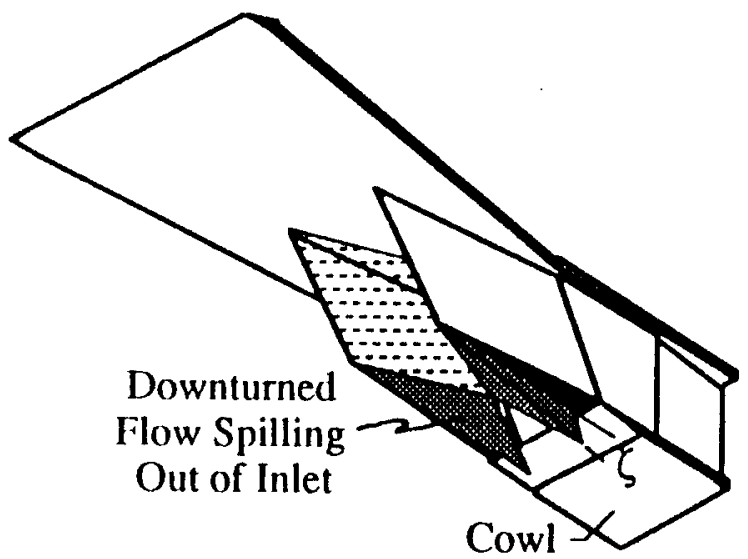

Figure 10: Flow Spillage Due to Swept Shock Sheet Emanating from Sidewall Leading Edge (Spillage Angle $\zeta$ is Exaggerated)

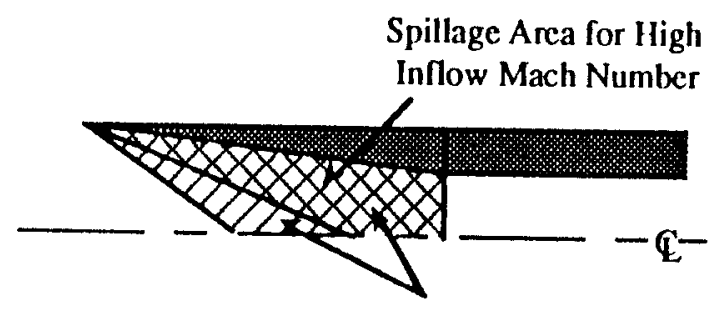

Spillage Area for Low Inflow Mach Number

Figure 11: Spillage Area (in plane of the cowl) for Low and High Inflow Mach Numbers 


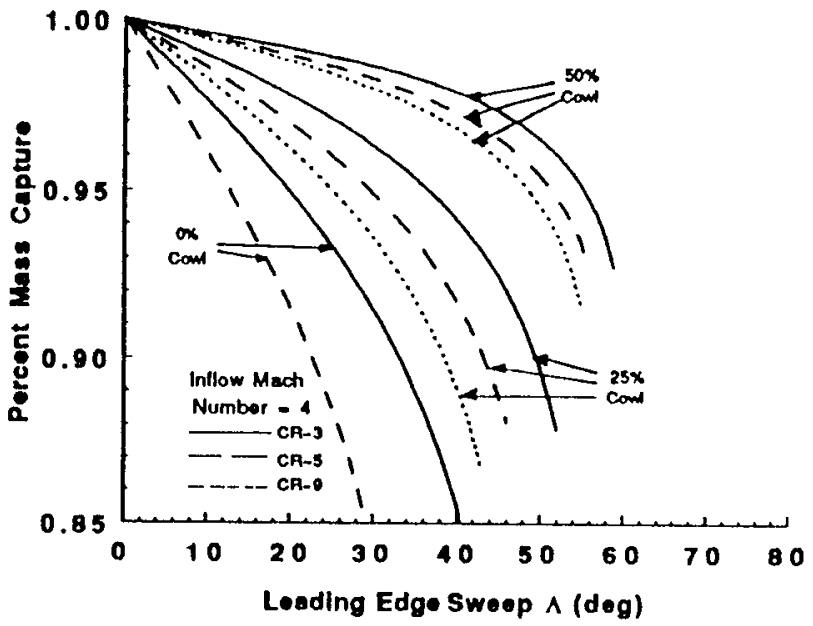

Figure 12: Contraction Ratio and Cowl Position Effects on Total Mass Capture for a Mach $4, \delta=6^{\circ}$ Inlet

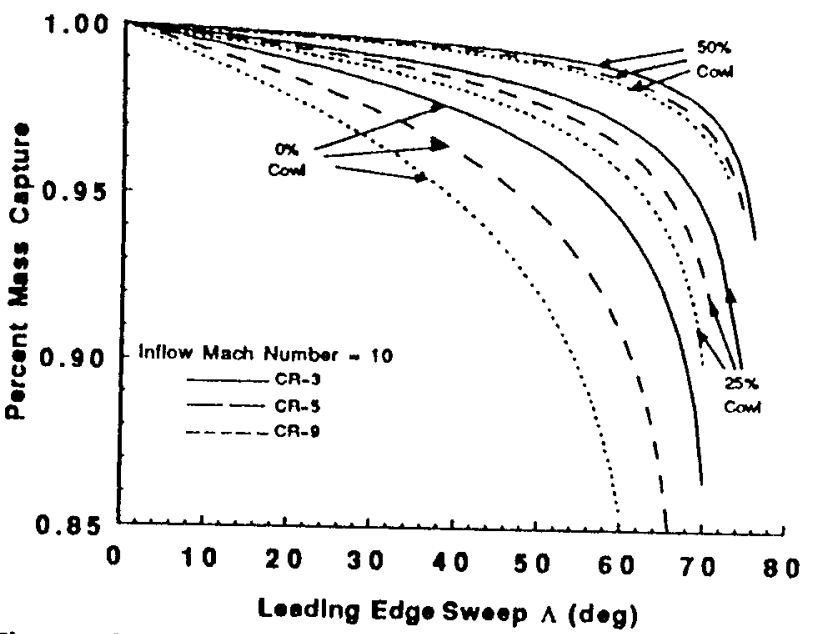

Figure 13: Contraction Ratio and Cowl Position Effects on Total Mass Capture for a Mach 10, $\delta=6^{\circ}$ Inlet

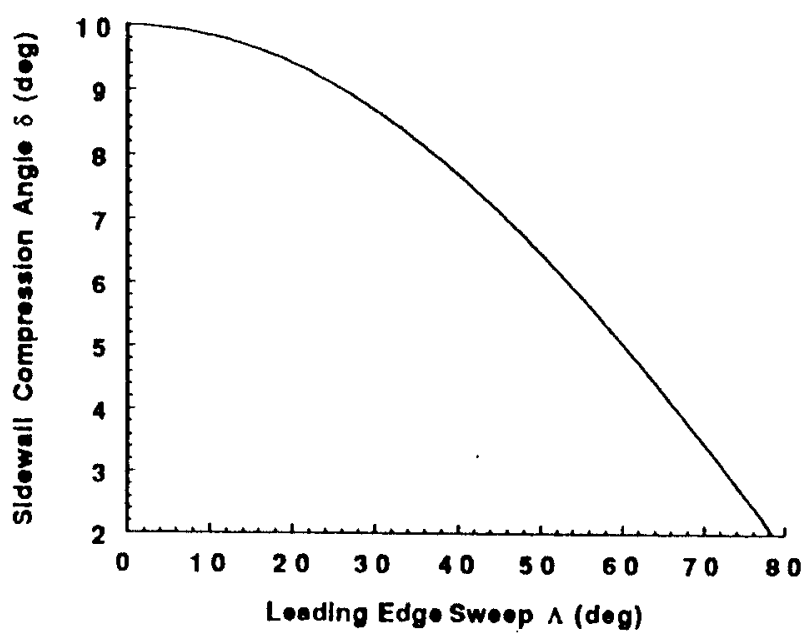

Figure 14: Sidewall Compression Angle as a Function of Leading Edge Swcep for Constant Effective Wedge Angle Class of Inlets

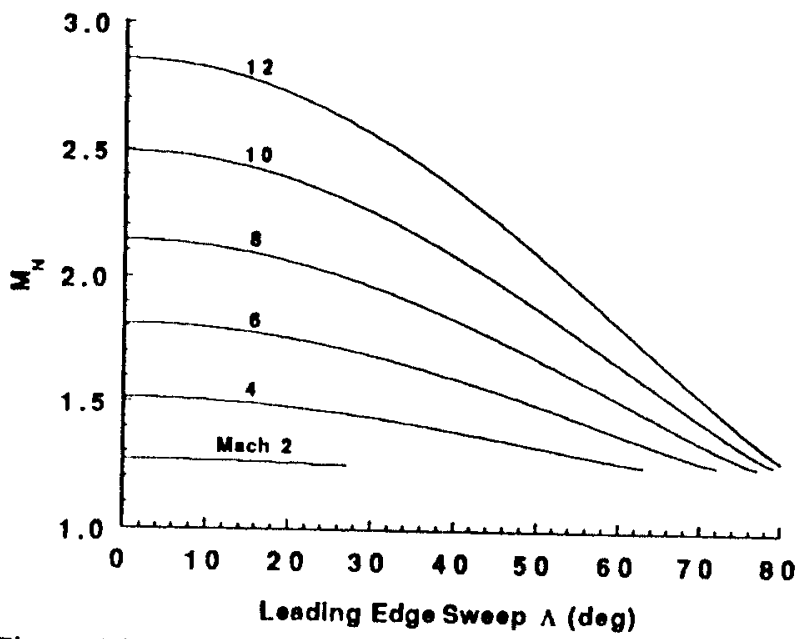

Figure 15: Mach Component Normal to Shock Sheet as a Function of Leading Edge Sweep for Constant Effective Wedge Angle Class of Inlets 


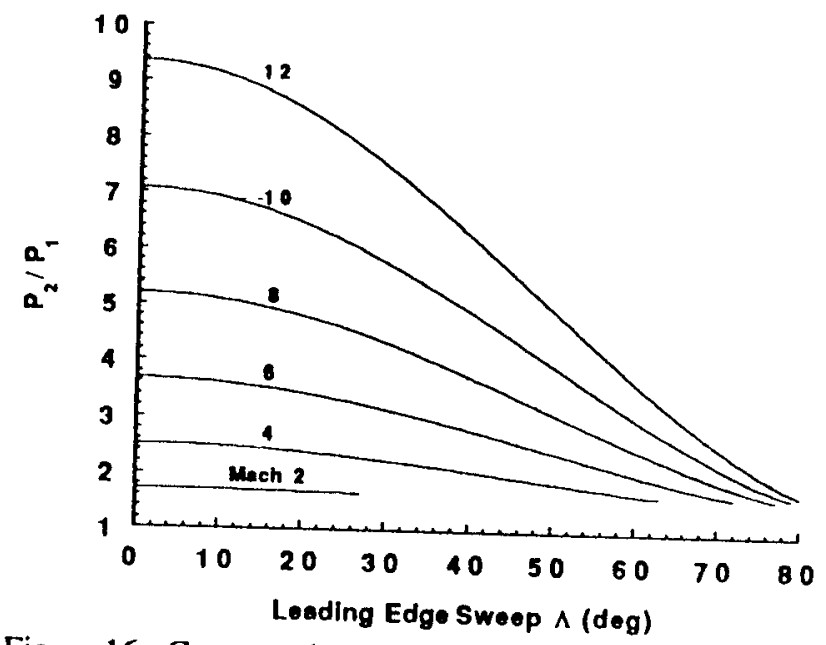

Figure 16: Compression Across Leading Edge Shock as a Function of Leading Edge Sweep for Constant Effective Wedge Angle Class of Inlets

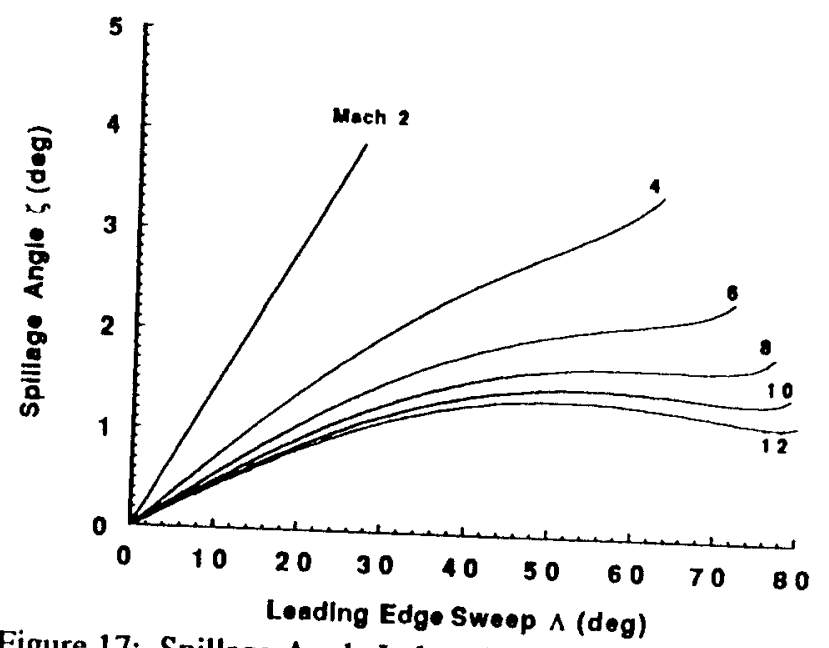

Figure 17: Spillage Angle Induced by Leading Edge Shock as a Funclion of Leading Edge Swecp for Constant Effective Wedge Angle Class of Inlets

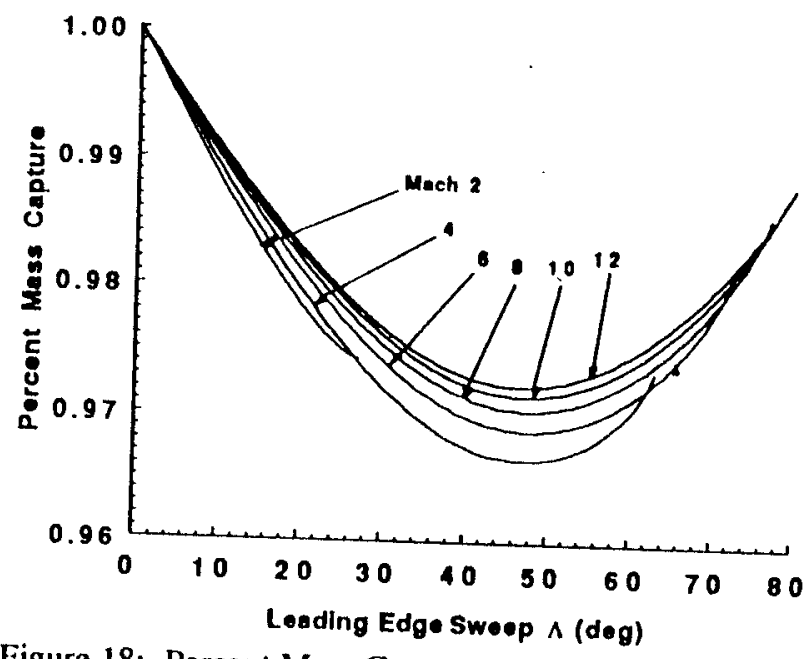

Figure 18: Percent Mass Capture Resulting from Spillage Induced by Leading Edge Shock as a Function of Sweep for Constant Efrective Wedge Angle 


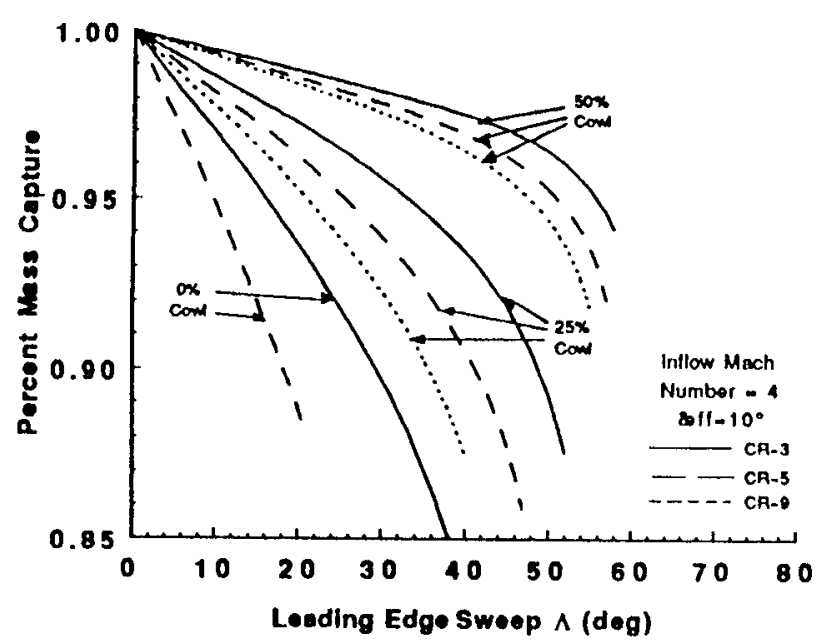

Figure 19: Contraction Ratio and Cowl Position Effects on Total Mass Capture for a Mach 4, $\delta_{\mathrm{cff}}=10^{\circ}$ Inlet

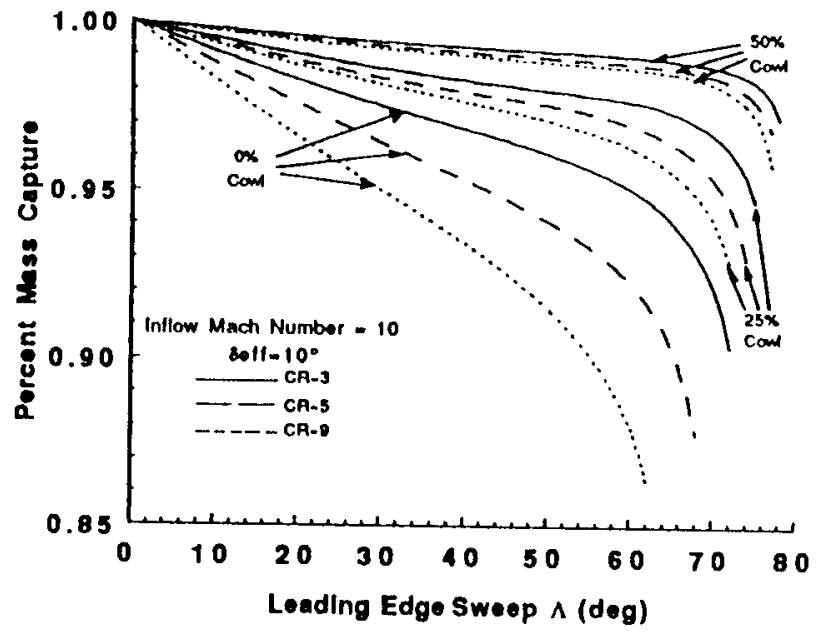

Figure 20: Contraction Ratio and Cowl Position Effects on Total Mass Capture for a Mach $10, \delta_{\mathrm{c} f}=10^{\circ}$ Inlet 